\title{
Dynorphin-(1-13): Antinociceptive Action and Its Effects on Morphine Analgesia and Acute Tolerance
}

\author{
Shiroh Kishioka, Naonori Morita, Yuji Kitabata, Tetsuji Yamanishi, Yoshiyuki Miyamoto, \\ Masanobu Ozaki and Hiroyuki Yamamoto \\ Department of Pharmacology, Wakayama Medical College, Wakayama 640, Japan \\ Received April 27, 1992 Accepted August 11, 1992
}

\begin{abstract}
Antinociceptive actions and effects of intracerebroventricular (i.c.v.) dynorphin-(1-13) (DYN) on morphine (MOR) analgesia and acute tolerance were studied in male Sprague-Dawley rats. Antinociceptive effect against hind paw pressure was produced by $30 \mu \mathrm{g}$ of $\mathrm{DYN}$, but not by $0.5-10$ $\mu \mathrm{g}$. Acetic acid writhing was inhibited dose-dependently by DYN at the doses of $2-30 \mu \mathrm{g}$, and the order of potency of the anti-writhing effect was $\beta$-endorphin $>$ MOR $>$ DYN $\gg$ Met-enkephalin. The anti-writhing effect of DYN that was partially antagonized by naloxone at $10 \mathrm{mg} / \mathrm{kg}$, s.c. in MOR tolerant rats was the same as that in MOR naive rats. The anti-writhing effect of i.c.v.-MOR was increased synergistically by DYN. Continuous s.c. $(6 \mathrm{mg} / \mathrm{kg} / \mathrm{hr})$ and i.c.v. $(7.5 \mu \mathrm{g} / \mathrm{rat} / \mathrm{hr})$ infusion of MOR produced antinociception against hind paw pressure, which reached maximum (MAX) and attenuated thereafter during MOR infusion for $6 \mathrm{hr}$. The attenuation of antinociception was also produced during MOR infusion combined with multiple i.c.v.-injection of DYN. The MAX and area under the antinociceptive curve during MOR infusion was not affected by multiple injection of DYN, i.e., no effect of i.c.v.-DYN on the development of acute MOR tolerance induced by s.c.- and i.c.v.-infusion was observed. In conclusion, the anti-writhing effect of i.c.v.-DYN might not be mediated via $m u$-receptors, although DYN increased the anti-writhing effect of i.c.v.-MOR synergistically and the development of acute tolerance to MOR (i.c.v., s.c.) was not affected by i.c.v.-DYN.
\end{abstract}

Keywords: Dynorphin-(1-13), Antinociception, Morphine analgesia, Acute tolerance

Dynorphin-(1-13) (DYN), was shown to be a potent opioid peptide during in vitro bioassays on guinea pig ileum and mouse vas deferens (1), and it has been suggested as an endogenous opioid ligand for the kappaopioid-receptor subtype (2). Immunohistochemical studies have demonstrated the regional distribution of dynorphin-contaning fibers in the brain (hypothalamus and periaqueductal gray matter) and spinal cord (dorsal horn) $(3,4)$. The kappa-opioid-receptor has also been found to have a parallel distribution in these same areas of the central nervous system $(5,6)$, which are known to participate in pain modulation. In addition, rats subjected to the chronic pain of polyarthritis were shown to exhibit a pronounced increase of dynorphin in the spinal cord (7). These results suggest a physiological role for dynorphin as an endogenous pain-modulator.

The antinociceptive action of dynorphins has been demonstrated by the tail pinch test $(8-10)$, hind paw pressure test (11), acetic acid $(\mathrm{AcOH})$-induced writhing test $(10,12)$ and cold water tail flick test $(13,14)$, but not by the radiant heat tail flick test (15).

It is known that, mu-, delta- and kappa-opioid-receptors play important roles in the modulation of pain (16). Although subtypes of opioid receptors are considered as entirely distinct entities, interactions between opioid receptor subtypes have been suggested by binding assays $(17,18)$. Selective up-regulation of kappaopioid-receptors in several brain regions and spinal cord has been shown in morphine (MOR) tolerant rats (19, 20) and kappa-agonists-induced increase in plasma corticosterone has been shown to be potentiated in MOR tolerant rat (21), but no study on DYN antinociception in the MOR tolerant state has been reported.

A modulatory role of dynorphin on MOR analgesia has been shown by the evidence that DYN, i.c.v. reduced the MOR analgesia in naive mice, but potentiated it in MOR tolerant ones $(15,22)$. However, these findings had been obtained with the radiant heat tail 
flick test which demonstrated an antinociceptive effect of MOR but not of dynorphin. Cold thermal and mechanical noxious stimuli evoked the release of substance P (SP) in the spinal cord, being blocked by dynorphin and MOR $(13,23)$. Hot thermal stimuli evoked the release of somatostatin, which was inhibited by MOR (24), but not the release of SP in the spinal cord $(13,24)$. These results may provide some underlying mechanisms for the evidence that MOR is sensitive against mechanical, cold-thermal and hot-thermal stimuli, while dynorphin is sensitive against machanical and cold-thermal stimuli. Therefore, it is questionable whether or not the modulatory effect of dynorphin on MOR analgesia estimated by the assays which can detect both dynorphin and MOR analgesia is the same as that estimated by the assay which can detect MOR analgesia but not dynorphin analgesia.

Involvement of dynorphin in the development of MOR tolerance has been suggested (22), and it was reported that concurrent treatment with U-50,488H, a highly selective agonist for kappa-opioid-receptors, blocked the development of tolerance to MOR (25). However, the effect of dynorphin on the development of tolerance to MOR has not been reported.

In the present study, the analgesic effects of DYN were reinvestigated by the $\mathrm{AcOH}$ writhing test and the hind paw pressure test, and the antinociceptive potency of DYN was compared with those of $\beta$-endorphin, MOR and methionine (Met)-enkephalin by the AcOH writhing test. In addition, the DYN-induced antinociceptive action in MOR tolerant rats and the DYN effect on MOR antinociception were investigated by the AcOH writhing test. Finally, the DYN effect on the development of acute tolerance to MOR induced by s.c.and i.c.v.-infusion was determined by the hind paw pressure test.

\section{MATERIALS AND METHODS}

\section{Animals}

Male Sprague-Dawley rats (Clea, Japan), weighing $200-300 \mathrm{~g}$, were used. Two rats were housed in each hanging wire cage in an animal room with controlled temperature $\left(23-24^{\circ} \mathrm{C}\right)$, humidity $(60-70 \%)$ and lighting $(8: 00-20: 00)$ for at least 2 weeks before the experiments. Food (CA-1, Clea Japan) and water were available ad libitum.

\section{Intracerebroventricular injection}

Rats were implanted stereotaxically on the skull with a 20-gauge guide cannula (hypodermic injection needle $1 / 1$, Viola) under pentobarbital $(50 \mathrm{mg} / \mathrm{kg}$, i.p.) anesthesia, according to the method of de Balbian Vester et al. (26). The coordinates were: $2 \mathrm{~mm}$ left lateral to the sagittal suture and $1 \mathrm{~mm}$ caudal to the coronal suture. A dummy stylet was left in the guide cannula until the drug administration. The rats were allowed at least 7 days of postoperative recovery before testing. Intracerebroventricular (i.c.v.)-injection was made by replacing the dummy stylet with a 29-gauge injection needle (hypodermic injection needle $1 / 5$, Viola), which was inserted $5 \mathrm{~mm}$ beyond the surface of the skull to bring its tip into the left lateral ventricle. Drugs were i.c.v.-administered in a volume of $10 \mu 1$ over $30 \mathrm{sec}$ periods using a microsyringe (Hamilton).

The i.c.v.-injection site was verificd by injection of cresyl violet dye in the same manner as the i.c.v.-injection of drug at the end of experiment.

\section{Antinociceptive assay}

Hind paw pressure test: The non-inflamed hind paw pressure threshold was assayed by an analgesy meter (Ugo Basile, Milan, Italy). A force that increased at a constant rate was applied to the dorsal hind paw, and the pain threshold was measured as the grams required to induce the flight reaction (struggle). A cut-off loading pressure of $1500 \mathrm{~g}$ was used to prevent tissue damage. The basal pain threshold was measured twice, 10 min apart, just before drug administration. The pain thresholds were measured every $10 \mathrm{~min}$ for $90 \mathrm{~min}$ after DYN, i.c.v. or every $15 \mathrm{~min}$ for $6 \mathrm{hr}$ during continuous infusion of MOR (s.c. or i.c.v.).

AcOH writhing test: Rats were injected i.p. with $3 \%$ AcOH solution $(0.1 \mathrm{ml} / 100 \mathrm{~g}$ body weight $) 5 \mathrm{~min}$ after i.c.v.-injection of the drug, and the writhing syndrome was observed for $60 \mathrm{~min}$ after $\mathrm{AcOH}$ injection.

\section{Induction of MOR tolerance}

Rats were rendered tolerant to MOR analgesia in two ways.

(i) MOR was administered subcutaneously for 3 days $(50,100$ and $100 \mathrm{mg} / \mathrm{kg} /$ day, divided into two doses, on day 1 , day 2 and day 3 , respectively). Analgesia was tested on day 4 according to the $\mathrm{AcOH}$ writhing method. (ii) MOR was infused subcutaneously $(6$ $\mathrm{mg} / \mathrm{kg} / \mathrm{hr}, 1 \mathrm{ml}$ of injection solution $/ \mathrm{hr} / \mathrm{rat}$, Roller pump, Furue Science, PR-V) or intracerebroventricularly $(7.5 \mu \mathrm{g} / \mathrm{rat} / \mathrm{hr}, 10 \mu \mathrm{l}$ of injection solution $/ \mathrm{hr} / \mathrm{rat}$, infusion pump, Truth A-II type) for $6 \mathrm{hr}$ at a constant rate. The pain threshold was estimated during MOR infusion by the hind paw pressure test.

\section{Drugs}

MOR (Morphine hydrochloride, Takeda Pharm.), DYN (dynorphin-(1-13), Peninsula Labo., Inc.), human $\beta$-endorphin (Peninsula Labo., Inc.), methionine 
(Met)-enkephalin (Peptide Institute, Inc.), acetic acid (Katayama Chem.) and sodium pentobarbital (Somnopentyl, Pitman Moore) were used. All drugs were dissolved in saline. The peptides were stored at $-80^{\circ} \mathrm{C}$ until use and other drugs were freshly prepared immediately before use. The injection volume for s.c.administration was $0.2 \mathrm{ml} / 100 \mathrm{~g}$ body weight.

\section{Statistical analysis}

Values were expressed as the mean \pm S.E.M. Data were analyzed by one-way analysis of variance (ANOVA) followed by Newman-Keuls test for multiple comparison, and the two-tailed Student's $t$-test was used for comparison between groups.

\section{RESULTS}

\section{Behavioral effect of DYN}

Barrel-rolling was elicited by the large doses of DYN, i.c.v. The incidence and the duration of the abnormal behavior induced by DYN at 10 and 30 $\mu \mathrm{g} / \mathrm{rat}$ was $22.0 \%$, for $2-3 \mathrm{~min}$, and $71.8 \%$, for $7-10$ $\mathrm{min}$, respectively. Abnormal behavior was not elicited by low doses of DYN $(0.5-2 \mu \mathrm{g} / \mathrm{rat}$ ), saline (i.c.v.), MOR $(0.65-30 \mu \mathrm{g} / \mathrm{rat}$, i.c.v.), $\beta$-endorphin $(0.65-5$ $\mu \mathrm{g} / \mathrm{rat}$, i.c.v.) and Met-enkephalin $(50-100 \mu \mathrm{g} / \mathrm{rat}$, i.c.v.). Barrel-rolling behavior was not prevented by pretreatment with the opioid antagonist, naloxone (10 $\mathrm{mg} / \mathrm{kg}$, s.c.), $5 \mathrm{~min}$ before DYN (data not shown).

\section{Antinociceptive effect of DYN}

Hind paw pressure test: The time course of the antinociceptive effect of DYN, i.c.v. is shown in Fig. 1. DYN at $0.5-10 \mu \mathrm{g} / \mathrm{rat}$ did not increase the pain threshold. DYN at $30 \mu \mathrm{g} / \mathrm{rat}$ produced a significant increase in the pain threshold at $10 \mathrm{~min}$ (saline vs. DYN, $30 \mu \mathrm{g} / \mathrm{rat} ; \mathrm{DYN}, 0.5 \mu \mathrm{g} / \mathrm{rat}$ vs. DYN, $30 \mu \mathrm{g} / \mathrm{rat}$; DYN, $2 \mu \mathrm{g} /$ rat vs. DYN, $30 \mu \mathrm{g} /$ rat; and DYN, 10 $\mu \mathrm{g} / \mathrm{rat}$ vs. DYN, $30 \mu \mathrm{g} / \mathrm{rat} ; \mathbf{P}<0.01$ ) and $20 \mathrm{~min}$ (saline vs. DYN, $30 \mu \mathrm{g} / \mathrm{rat}$; DYN, $0.5 \mu \mathrm{g} / \mathrm{rat}$ vs. DYN, $30 \mu \mathrm{g} / \mathrm{rat} ; \mathrm{DYN}, 2 \mu \mathrm{g} / \mathrm{rat}$ vs. DYN, $30 \mu \mathrm{g} / \mathrm{rat}$; and DYN, $10 \mu \mathrm{g} / \mathrm{rat}$ vs. DYN, $30 \mu \mathrm{g} / \mathrm{rat} ; \mathrm{P}<0.05$ ) after injection; the pain threshold was restored to the predrug control threshold $30-40 \mathrm{~min}$ after injection.

AcOH writhing test: Anti-writhing effects of DYN and other opioid agonists: $\mathrm{ACOH}$ induced writhing was not affected by saline, i.c.v. (Fig. 2). DYN at 2-30 $\mu \mathrm{g} / \mathrm{rat}$ suppressed writings in a dose-related manner $(0$ $-15 \mathrm{~min}$ and $0-30 \mathrm{~min}: \mathrm{SAL}$ vs. DYN, $30 \mu \mathrm{g} / \mathrm{rat}, \mathrm{P}<$ $0.05 ; 0-60 \mathrm{~min}$ : None vs. DYN, $30 \mu \mathrm{g} / \mathrm{rat}$ and SAL vs. DYN, $30 \mu \mathrm{g} / \mathrm{rat}, \mathrm{P}<0.05$ ), and the suppressive effect of DYN at $30 \mu \mathrm{g} / \mathrm{rat}$ was almost equipotent to that of MOR at $1 \mu \mathrm{g} / \mathrm{rat}$, i.c.v. (Fig. 2).

Anti-AcOH writhing potencies of MOR, $\beta$-endor-

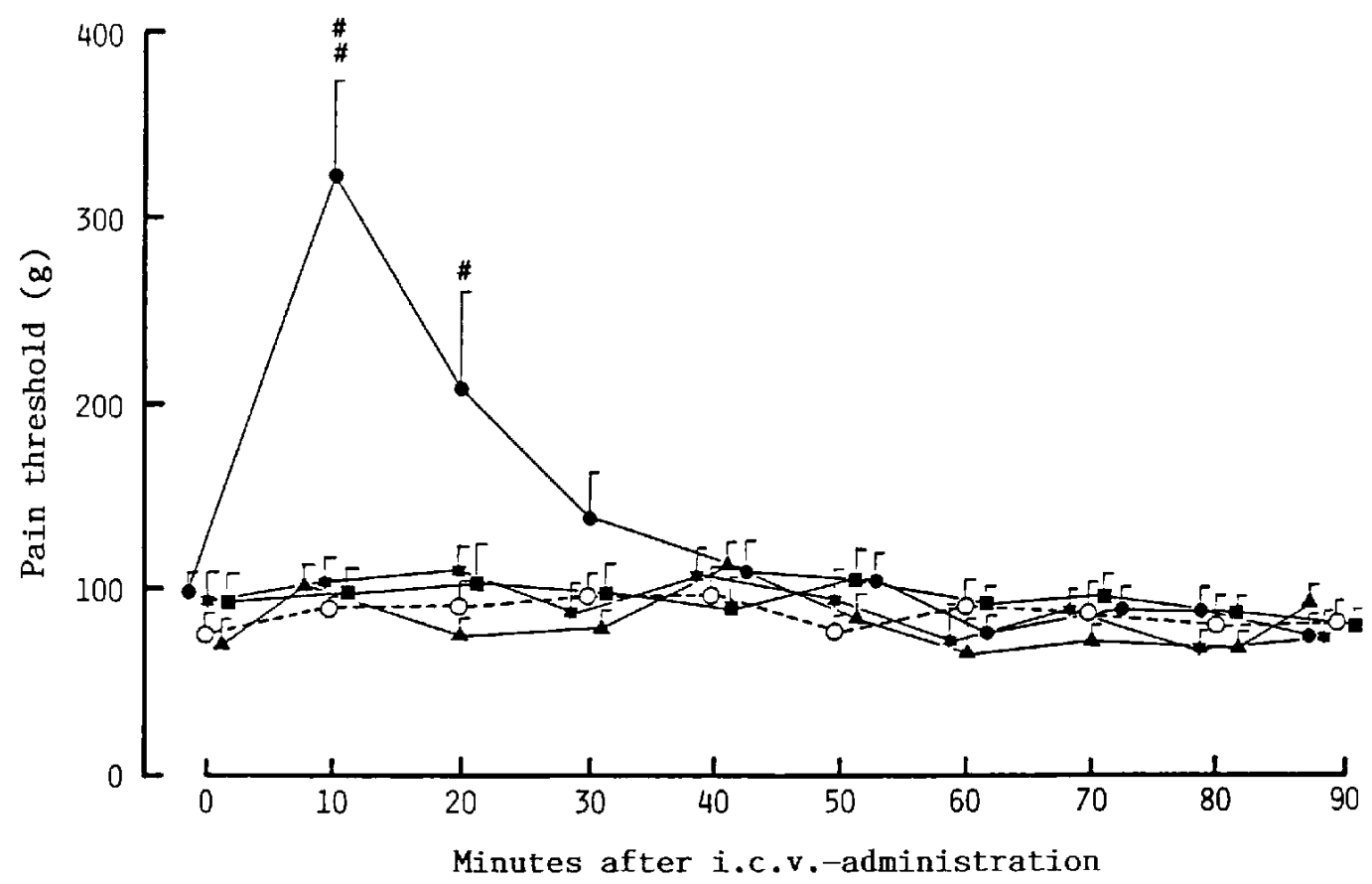

Fig. 1. Time courses of the antinociceptive effect of dynorphin- $(1-13)(0.5-30 \mu \mathrm{g} / \mathrm{rat}$, i.c.y.) estimated by the hind paw pressure test. $\bigcirc$ : Saline; $*$ DYN, $0.5 \mu \mathrm{g} / \mathrm{rat}$; $\boldsymbol{D}: \mathrm{DYN}, 2 \mu \mathrm{g} / \mathrm{rat} ; \boldsymbol{\Delta}: \mathrm{DYN}, 10 \mu \mathrm{g} / \mathrm{rat}$; $: \mathrm{DYN}, 30 \mu \mathrm{g} / \mathrm{rat}$. Abbreviation: DYN, dynorphin-(1-13). Each value is the mean, and vertical bars indicate the S.E.M. of 5 rats. Differs from saline,

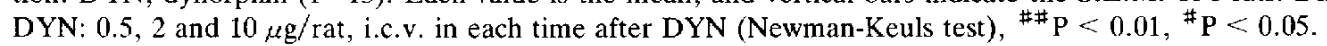




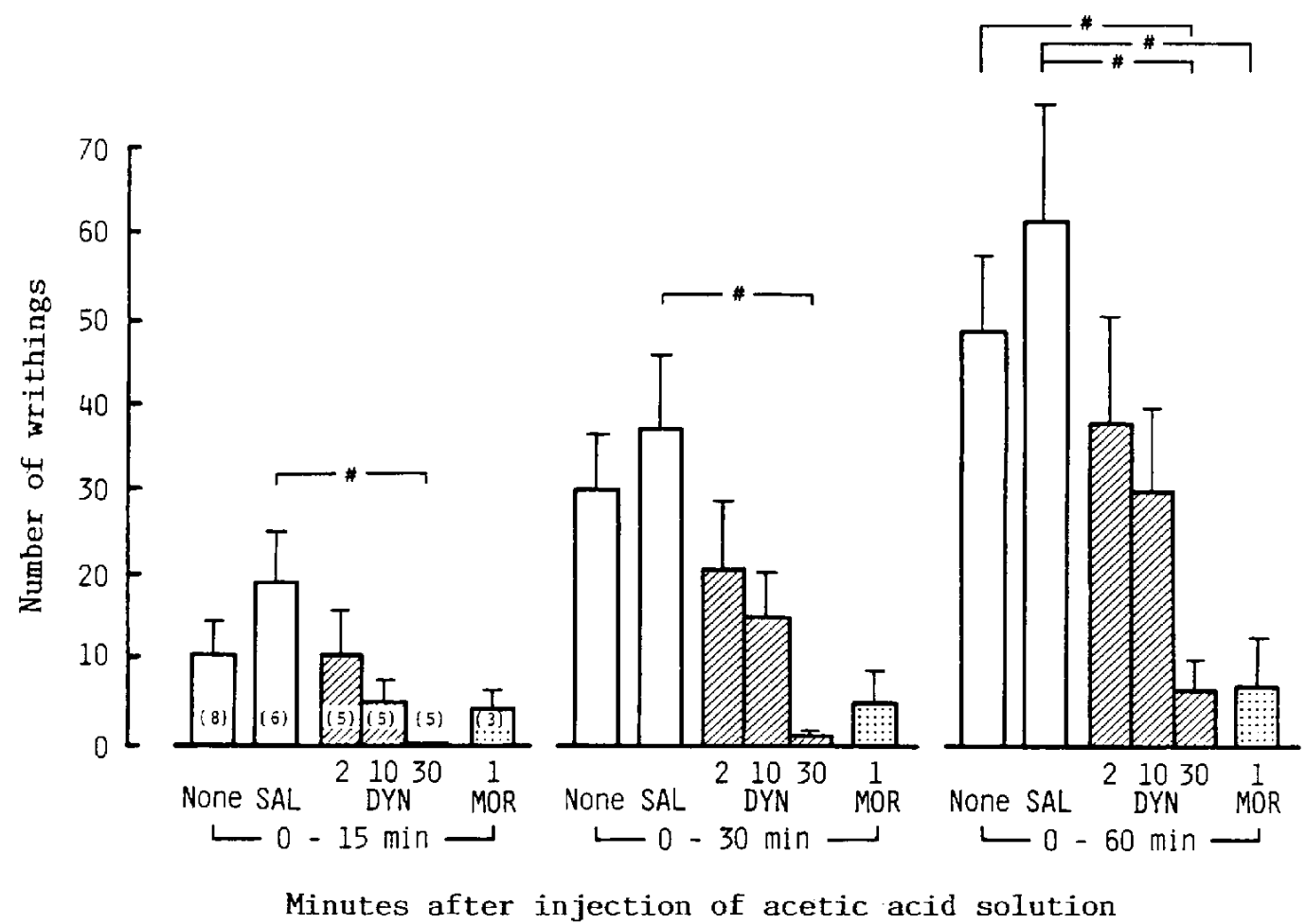

Fig. 2. Anti-writhing effects of dynorphin-(1-13), i.c.v. A $3 \%$-solution of acetic acid was injected intraperitoneally 5 min after dynorphin-(1-13), i.c.v. Abbreviations: None, nontreatment (neither operation nor salinc administration); SAL, saline; DYN, dynorphin-(1-13); MOR, morphine. Numbers on "DYN" and "MOR" represent the doses ( $\mu \mathrm{g} / \mathrm{rat}$, i.c.v.). Each column and vertical bar indicates the mean and S.E.M. of writhings for $0-15,0-30$ or $0-60$ min after injection of acetic acid solution. Number in the column is number of experiments. Statistical difference (Newman-Keuls test), ${ }^{\#} \mathrm{p}<$ 0.05 .

phin, Met-enkephalin and DYN, each given i.c.v., were compared (Table 1). As $\beta$-endorphin at $1 \mu \mathrm{g} /$ rat (preliminary study), MOR at $1 \mu \mathrm{g} / \mathrm{rat}$ and DYN at 30 $\mu \mathrm{g} /$ rat (Fig. 2) almost completely suppressed writhings, i.c.v.-doses of $0.65 \mu \mathrm{g} / \mathrm{rat}, 0.65 \mu \mathrm{g} / \mathrm{rat}$ and $20 \mu \mathrm{g} / \mathrm{rat}$ were selected for the test doses of $\beta$-endorphin, MOR and DYN, respectively. The anti-writhing effects of DYN, $\beta$-endorphin and MOR were almost the same at the doses used, and the order of potency of the antiwrithing effect was $\beta$-endorphin $>\mathrm{MOR}>\mathrm{DYN}$, based on the molar doses. The anti-writhing effect of Met-enkephalin, although the dose was prominently

Table 1. Anti-writhing effects of dynorphin-(1-13) and other opioid agonists given i.c.v.

\begin{tabular}{lccccc}
\hline \multicolumn{1}{c}{ Agents } & $\begin{array}{c}\text { Dose } \\
\text { nmol/rat, i.c.v. } \\
(\mu \mathrm{g} / \text { rat, i.c.v. })\end{array}$ & $\mathrm{n}$ & \multicolumn{2}{c}{ Inhibition of writhing $(\%)$} \\
\hline Dynorphin-(1-13) & $\begin{array}{c}12.47 \\
(20)\end{array}$ & 11 & $82.8 \pm 8.7$ & $70.6 \pm 10.0$ & $53.7 \pm 15.1$ \\
$\beta$-Endorphin & 0.19 & 11 & $97.0 \pm 3.0$ & $96.7 \pm 1.4$ & $95.5 \pm 1.8$ \\
Morphine & $(0.65)$ & 11 & $89.9 \pm 5.3$ & $90.8 \pm 3.8$ & $88.7 \pm 4.4$ \\
Met-enkephalin & 1.73 & 11 & $23.4 \pm 23.0$ & $36.0 \pm 19.4$ & $35.9 \pm 18.2$ \\
& $(0.65)$ & & & & \\
\hline
\end{tabular}

A $3 \%$-solution of acetic acid was intraperitonealy irjected 5 min after drugs, i.c.v. Each datum represcnts the mean \pm S.E.M. of percent inhibition of writhings for $0-15,0-30$ or $0-60 \mathrm{~min}$ after injection of acetic acid solution. " $n$ " is the number of experiments. 
larger than that of other agonists, was weaker than those of the other agonists. Although the suppression of writhing by $\beta$-endorphin, MOR and Met-enkephalin were fairly constant for the test period of $0-15,0-30$ and $0-60 \mathrm{~min}$ after i.p.-injection of $\mathrm{ACOH}$, the suppressive effect of DYN tended to decrease test-period dependently. These results may suggest that the duration of the suppressive effect of DYN is shorter than that of $\beta$-endorphin, MOR and Met-enkephalin.

Naloxone reversal of $D Y N$ effect: The effects of naloxone on inhibition of writhing by MOR, i.c.v. and DYN, i.c.v. are shown in Fig. 3. The animals were pretreated with naloxone, s.c. $5 \mathrm{~min}$ before MOR or DYN. No effect of naloxone alone on the AcOH writhing was observed. Although DYN at $30 \mu \mathrm{g} /$ rat in nontreated rats suppressed writhings significantly $(0-15$ $\min :$ SAL vs. DYN, $30 \mu \mathrm{g} / \mathrm{rat}, \mathbf{P}<0.05 ; 0-30 \mathrm{~min}$ : DYN, $10 \mu \mathrm{g} /$ rat vs. DYN, $30 \mu \mathrm{g} /$ rat, $\mathrm{P}<0.05$; SAL vs. DYN, $30 \mu \mathrm{g} / \mathrm{rat}, \mathrm{P}<0.01 ; 0-60 \mathrm{~min}: \mathrm{DYN}, 10$ $\mu \mathrm{g} /$ rat vs. DYN, $30 \mu \mathrm{g} /$ rat, $\mathrm{P}<0.05$; SAL vs. DYN $30 \mu \mathrm{g} /$ rat, $\mathrm{P}<0.01$ ), the anti-writhing effect of DYN at $30 \mu \mathrm{g} / \mathrm{rat}$ was not significant after pretreatment with naloxone at $10 \mathrm{mg} / \mathrm{kg}$, s.c. $(0-15 \mathrm{~min}, 0-30 \mathrm{~min}$ and $0-60 \mathrm{~min}:$ SAL vs. DYN, $10 \mu \mathrm{g} /$ rat vs. DYN, 30 $\mu \mathrm{g} / \mathrm{rat}, \mathrm{P}>0.05$ ). While MOR-induced suppression of writhing was reversed significantly by naloxone, there was no significant difference between writhings after DYN with and without naloxone. Naloxone at $1 \mathrm{mg} / \mathrm{kg}$, which completely antagonized the anti-writhing effect of MOR, did not affect the suppressive effect of DYN (data not shown). It might thus be judged that naloxone at $10 \mathrm{mg} / \mathrm{kg}$ partially antagonized the anti-writhing effect of DYN.

\section{Antinociceptive effect of DYN in MOR tolerant rats}

There was no significant difference in the numbers of writhings of naive-saline, i.c.v. and MOR treatedsaline, i.c.v. rats (Fig. 4). MOR at $1 \mu \mathrm{g} / \mathrm{rat}$, which produced a significant anti-writhing effect in naive rats, did not suppress writhing in MOR treated rats (Fig. 4), indicating the development of tolerance to the antiwrithing effect of MOR by the 3-day treatment with

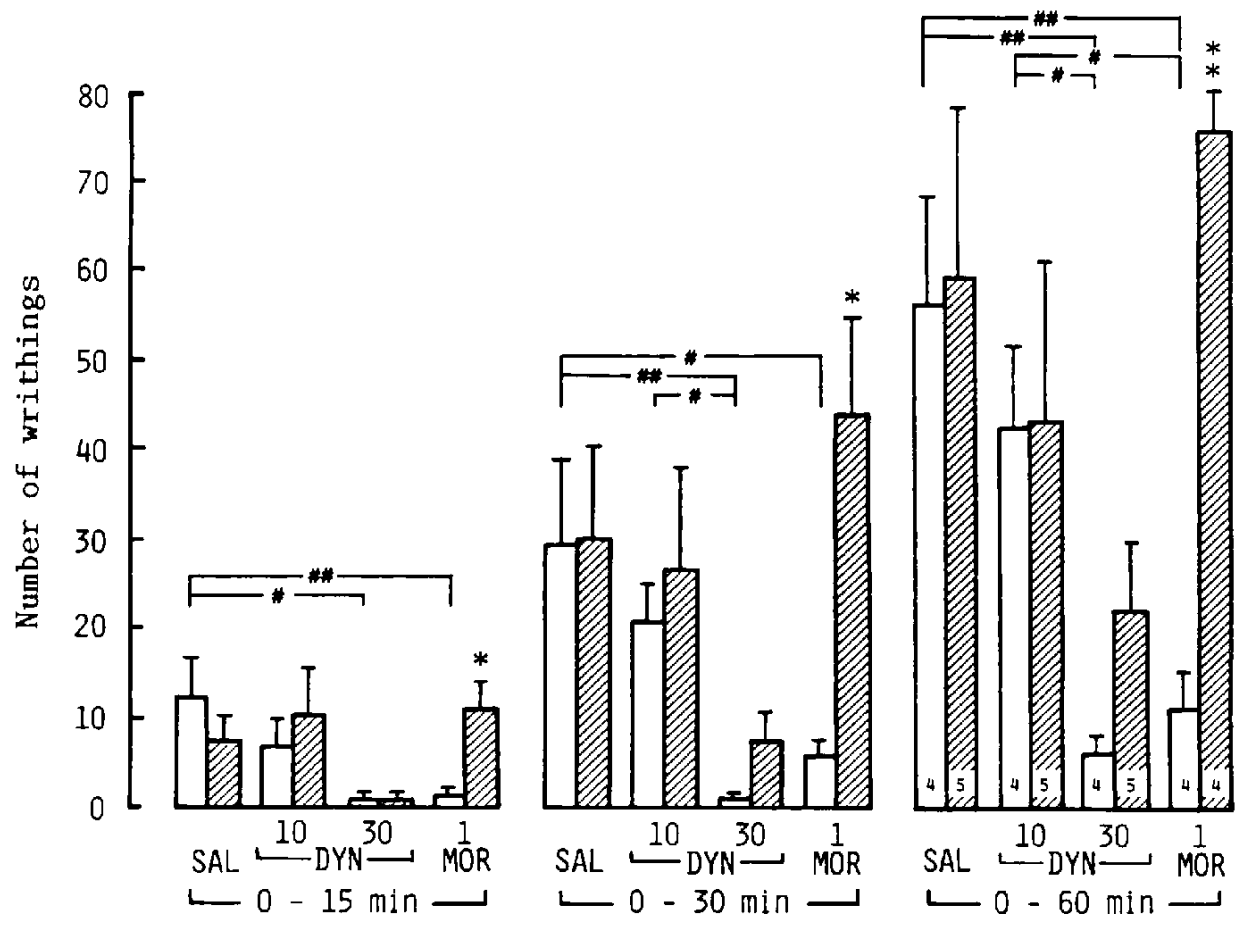

Minutes after injection of acetic acid solution

Fig. 3. Effect of naloxone on the anti-writhing effects of dynorphin-(1-13), i.c.v. A 3\%-solution of acetic acid was injected intraperitoneally $5 \mathrm{~min}$ after dynorphin-(1-13), i.c.v. Numbers on "DYN" and "MOR" represent the doses $(\mu \mathrm{g} / \mathrm{rat}$, i.c.v.). Naloxone $(10 \mathrm{mg} / \mathrm{kg}$. s.c.) was injected $5 \mathrm{~min}$ before dynorphin-(1-13) and morphine, i.c.v. Abbreviations: SAL, saline; DYN, dynorphin-(1-13); MOR, morphine. Each column and vertical bar indicates the mean and S.E.M. of writhings for $0-15,0-30$ or $0-60 \mathrm{~min}$ after injection of acetic acid solution. Number in the column is number of experiments. Statistical difference (Newman-Keuls test), ${ }^{\# \#} \mathrm{P}<0.01,{ }^{\#} \mathrm{P}<0.05$. Differs from nontreatment (Student's t-test), ${ }^{* *} \mathrm{P}<0.01,{ }^{*} \mathrm{P}<0.05 . \square$ : Nontreatment, $\mathbb{2}$ : Naloxone, $10 \mathrm{mg} / \mathrm{kg}$, s.c. 

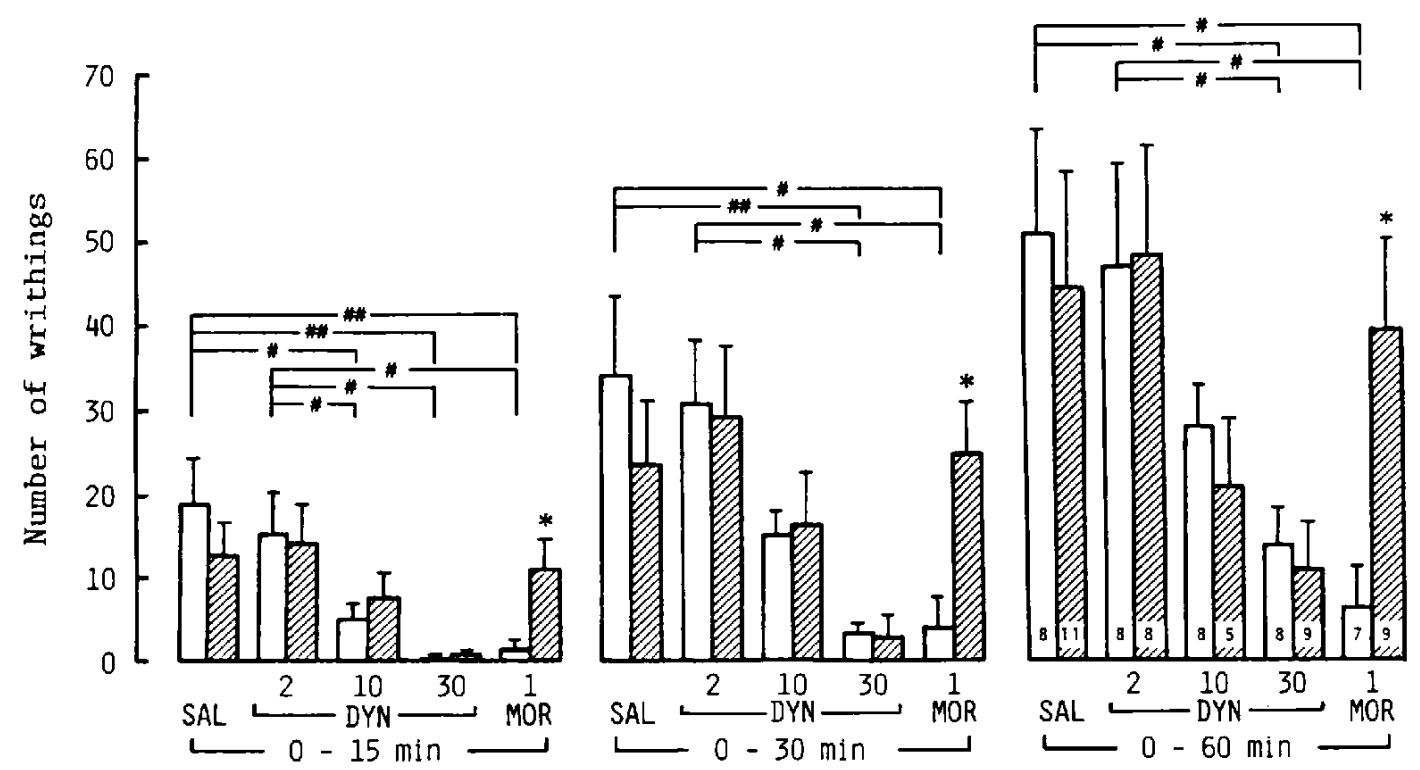

Minutes after injection of acetic acid solution

Fig. 4. Anti-writhing effects of dynorphin-(1-13), i.c.v. in morphine tolerant rats. A $3 \%$-solution of acetic acid was intraperitoneally injected $5 \mathrm{~min}$ after dynorphin-(1-13), and morphine, i.c.v. Numbers on "DYN" and "MOR" represent the doses $(\mu \mathrm{g} / \mathrm{rat}$, i.c.v.). For the development of morphine tolerance, morphine was injected for 3 days (details in method). Abbreviations: SAL, saline; DYN, dynorphin-(1-13); MOR, morphine. Each column and vertical bar indicates the mean and S.E.M. of writhings for $0-15,0-30$ or $0-60$ min after injection of acetic acid solution. Number in the column is number of experiments. Statistical difference (Newman-Keuls test), ${ }^{\# \#} P<0.01 .{ }^{\#} P<0.05$. Differs from Naive rats (Student's $t$-test), ${ }^{*} \mathrm{P}<0.05 . \square$ : Naive, Morphine tolerant.

MOR. DYN at $2-30 \mu \mathrm{g} /$ rat produced a dose-dependent suppression of writhing in naive rats $(0-15 \mathrm{~min}$ : SAL vs. DYN, $10 \mu \mathrm{g} / \mathrm{rat}$; DYN, $2 \mu \mathrm{g} /$ rat vs. DYN, 10 $\mu \mathrm{g} /$ rat and DYN, $2 \mu \mathrm{g} /$ rat vs. DYN, $30 \mu \mathrm{g} /$ rat, $\mathrm{P}<$ 0.05 ; SAL vs. DYN, $30 \mu \mathrm{g} /$ rat, $\mathrm{P}<0.01 ; 0-30 \mathrm{~min}$ : DYN, $2 \mu \mathrm{g} / \mathrm{rat}$ vs. DYN, $30 \mu \mathrm{g} / \mathrm{rat}, \mathrm{P}<0.05$; SAL vs. DYN, $30 \mu \mathrm{g} / \mathrm{rat}, \mathbf{P}<0.01 ; 0-60 \mathrm{~min}: \mathrm{SAL}$ vs. DYN, $30 \mu \mathrm{g} / \mathrm{rat}$ and DYN, $2 \mu \mathrm{g} / \mathrm{rat}$ vs. DYN, $30 \mu \mathrm{g} / \mathrm{rat}, \mathrm{P}<$ 0.05 ). The intensity of $\mathrm{DYN}$-induced suppression of writhing in MOR tolerant rats was the same as that in naive rats (Fig. 4). These results show clearly that there is no significant influence of MOR tolerance on the antinociceptive effect of DYN.

\section{Effect of DYN on MOR antinociception}

The influence of DYN on MOR antinociception was estimated by the AcOH writhing test (Fig. 5). The rats were pretreated with DYN at $2-30 \mu \mathrm{g} /$ rat at $30 \mathrm{~min}$ before MOR i.c.v.-injection. The number of writhings $(0-60 \mathrm{~min}$ after $\mathrm{AcOH})$ of Sal-MOR treated rats (MOR $1 \mu \mathrm{g} / \mathrm{rat}$, pretreated with saline, i.c.v.) was about $30 \%$ of that of Sal-SAL treated rats (saline, i.c.v; pretreated with saline, i.c.v.). The suppressive effect of MOR on writhing tended to be enhanced by the pretreatment with DYN at 10 and $30 \mu \mathrm{g} / \mathrm{rat}$. The number of writhings $(0-60$ min after $\mathrm{AcOH})$ of DYN 30-SAL treated rats (saline, i.c.v.; pretreated with DYN, 30 $\mu \mathrm{g} / \mathrm{rat}$ ) was about $50 \%$ of that of Sal-SAL treated rats. The number of writhings of DYN 30-MOR treated rats (MOR, $1 \mu \mathrm{g} / \mathrm{rat}$; pretreated with DYN, $30 \mu \mathrm{g} /$ rat) was about $40 \%$ of that of Sal-MOR treated rats (MOR, 1 $\mu \mathrm{g} /$ rat; pretreated with saline, i.c.v.). These results indicate that the enhancement of MOR antinociception by DYN may be due to the synergistic interaction between them.

Effects of DYN on the development of acute MOR tolerance

Effect on acute MOR tolerance induced by s.c.-infusion: The pain threshold was estimated by the hind paw pressure test during $360 \mathrm{~min}$ of s.c.-MOR-infusion, and the area under the time-response curve (AUC, $\mathrm{kg} \times$ $\mathrm{min})$ was calculated for each rat.

Infusion of MOR $(6 \mathrm{mg} / \mathrm{kg} / \mathrm{hr}$, s.c. $)$ produced an increase in pain threshold, which attained maximum (maximum effect, MAX) at $135 \mathrm{~min}$ of MOR infusion and gradually waned in spite of the continuous infusion of MOR $(135 \mathrm{~min}-360 \mathrm{~min}: \mathrm{F}(15,80)=9.39, \mathrm{P}<0.01$; Fig. 6). This result indicates that acute tolerance to MOR antinociception was developed by s.c.-infusion of 


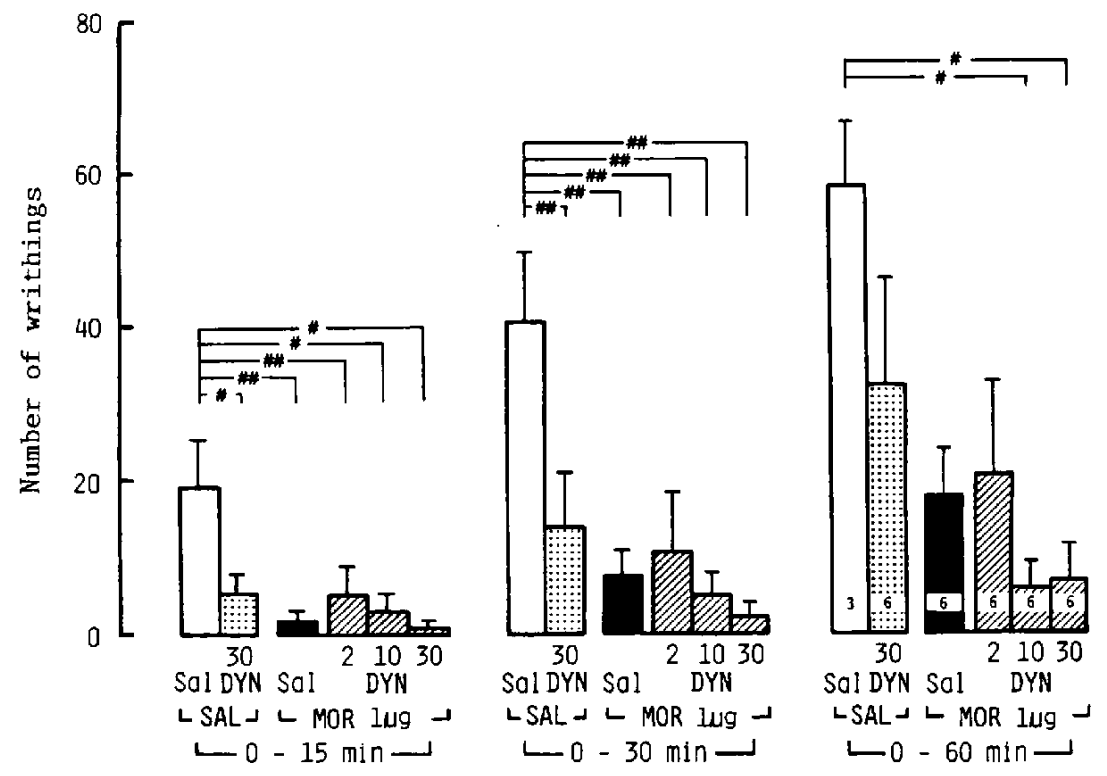

Minutes after injection of acetic acid solution

Fig. 5. Effect of pretreatment with dynorphin-(1-13), i.c.v. on the antinociceptive action of morphine (1 $\mu \mathrm{g} / \mathrm{rat}$, i.c.v.) estimated by the acetic acid writhing test. Dynorphin-(1-13), i.c.v. was pretreated 30 min before morphine, i.c.v. A $3 \%-$ solution of acetic acid was intraperitoneally injected 5 min after morphine, i.c.v. Numbers on "DYN" represent the doses ( $\mu \mathrm{g} / \mathrm{rat}$, i.c.v.). Sal, saline pretreatment; DYN, dynorphin-(1-13), pretreatment; SAL, saline, i.c.v.; MOR, morphine, i.c.v. Each column and vertical bar indicates the mean and S.E.M. of writhings for $0-15,0-30$ or $0-60$ min after injection of acetic acid solution. Number in the column is number of experiments. Statistical difference (Newman-Keuls test), ${ }^{\# \#} \mathrm{P}<0.01,{ }^{\#} \mathrm{P}<0.05$.

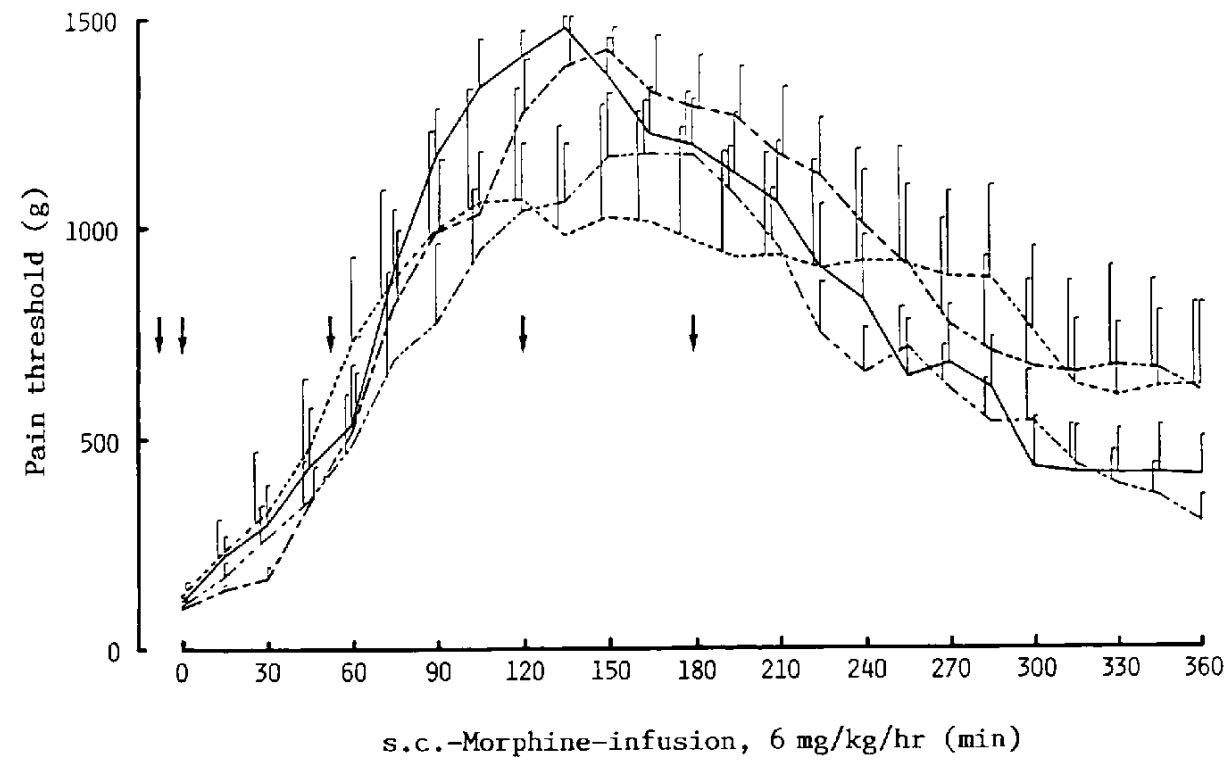

Fig. 6. Effect of dynorphin- $(1-13)$, i.c.v. on acute tolerance developed by continuous s.c.-infusion of morphine estimated by the hind paw pressure test. Morphine was s.c.-infused continuously at the rate of $6 \mathrm{mg} / \mathrm{kg} / \mathrm{hr}$ for $6 \mathrm{hr}$. Dynorphin-(113), i.c.v. was injected $1 \mathrm{hr}$ before, immediately before, and after 1,2 and $3 \mathrm{hr}$ of morphine infusion (arrows indicate the injection time of dynorphin-(1-13) in each dose). - - : MOR + SAL, -- : MOR + DYN, $2 \mu \mathrm{g} / \mathrm{rat} ;-\cdots:$ MOR + DYN, $10 \mu \mathrm{g} / \mathrm{rat} ; \cdots .$. MOR + DYN, $30 \mu \mathrm{g} /$ rat. MOR, continuous s.c.-infusion of morphine; SAL, saline, i.c.v.-treatment; DYN, dynorphin-(1-13), i.c.v-treatment. Each value is the mean, and vertical bars indicate the S.E.M. of 6 rats. No statistical difference among the four groups at each time after MOR infusion (Newman-Keuls test). 
MOR within $6 \mathrm{hr}$.

DYN at $2-30 \mu \mathrm{g} /$ rat, i.c.v. was injected 5 times: $1 \mathrm{hr}$ before, immediately before, and after 1,2 and $3 \mathrm{hr}$ of MOR infusion. No significant changes in MAX of s.c.infused MOR were produced by coadministration of DYN, i.c.v., although MAX showed a tendency to decrease by DYN at 10 and $30 \mu \mathrm{g} / \mathrm{rat}$, i.c.v. Decrease in pain thresholds after MAX during MOR infusion combined with DYN at 2 or $10 \mu \mathrm{g} / \mathrm{rat}$ was significant $(150$ $\min -360 \min : \mathrm{F}(14,75)=2.99, \mathrm{P}<0.01 ; 165 \min -360$ $\min : F(13,70)=7.38, P<0.01$, respectively), indicating the development of MOR tolerance even with the coadministration of DYN. Significant decrease in pain threshold after MAX (150 min - 360 min) during MOR infusion combined with $\mathrm{DYN}$ at $30 \mu \mathrm{g} / \mathrm{rat}$ was not observed $(\mathrm{F}(14,75)=0.35, \mathrm{P}>0.05)$, but there was no significant difference between pain thresholds during MOR alone and that during MOR combined with DYN at $30 \mu \mathrm{g} / \mathrm{rat}$. The AUCs for MOR combined with saline, i.c.v., DYN at $2 \mu \mathrm{g} / \mathrm{rat}, \mathrm{DYN}$ at $10 \mu \mathrm{g} / \mathrm{rat}$ and DYN at $30 \mu \mathrm{g} / \mathrm{rat}$ were $250.0 \pm 31.5(\mathrm{n}=6), 277.3 \pm$ $37.8(\mathrm{n}=6), 211.7 \pm 33.2(\mathrm{n}=6)$ and $238.0 \pm 73.0(\mathrm{n}$ $=6$ ), respectively. There was no statistically significant difference among the AUCs, in each group. DYN at 2 $-30 \mu \mathrm{g} / \mathrm{rat}$ at $1,2,3$ and $4 \mathrm{hr}$ of MOR infusion also did not affect the AUC and MAX; and a significant decrease in pain threshold after MAX was observed in all the DYN-MOR combined groups (data not shown). These results indicate that DYN at $2-30 \mu \mathrm{g} / \mathrm{rat}$, i.c.v. did not affect the development of acute tolerance to MOR antinociception by continuous s.c. infusion of MOR.

Effect on acute MOR tolerance induced by i.c.v.-infusion: The pain threshold was estimated by the hind paw pressure test during $360 \mathrm{~min}$ of i.c.v.-MOR infusion, and the AUC was calculated for each rat.

Continuous i.c.v.-infusion of saline produced no significant change of the pain threshold. Continuous i.c.v. infusion of MOR at the rate of $7.5 \mu \mathrm{g} / \mathrm{rat} / \mathrm{hr}$ increased the pain threshold, which attained MAX at $75 \mathrm{~min}$ of MOR infusion. The pain thresholds after MAX were significantly reduced $(75 \mathrm{~min}-360 \mathrm{~min}: \quad F(19,40)=$ $3.05, \mathrm{P}<0.01)$ in spite of the cotinuous infusion of MOR (Fig. 7). This result indicates that the acute tolerance to MOR antinociception was also developed by i.c.v.-infusion of MOR within $6 \mathrm{hr}$.

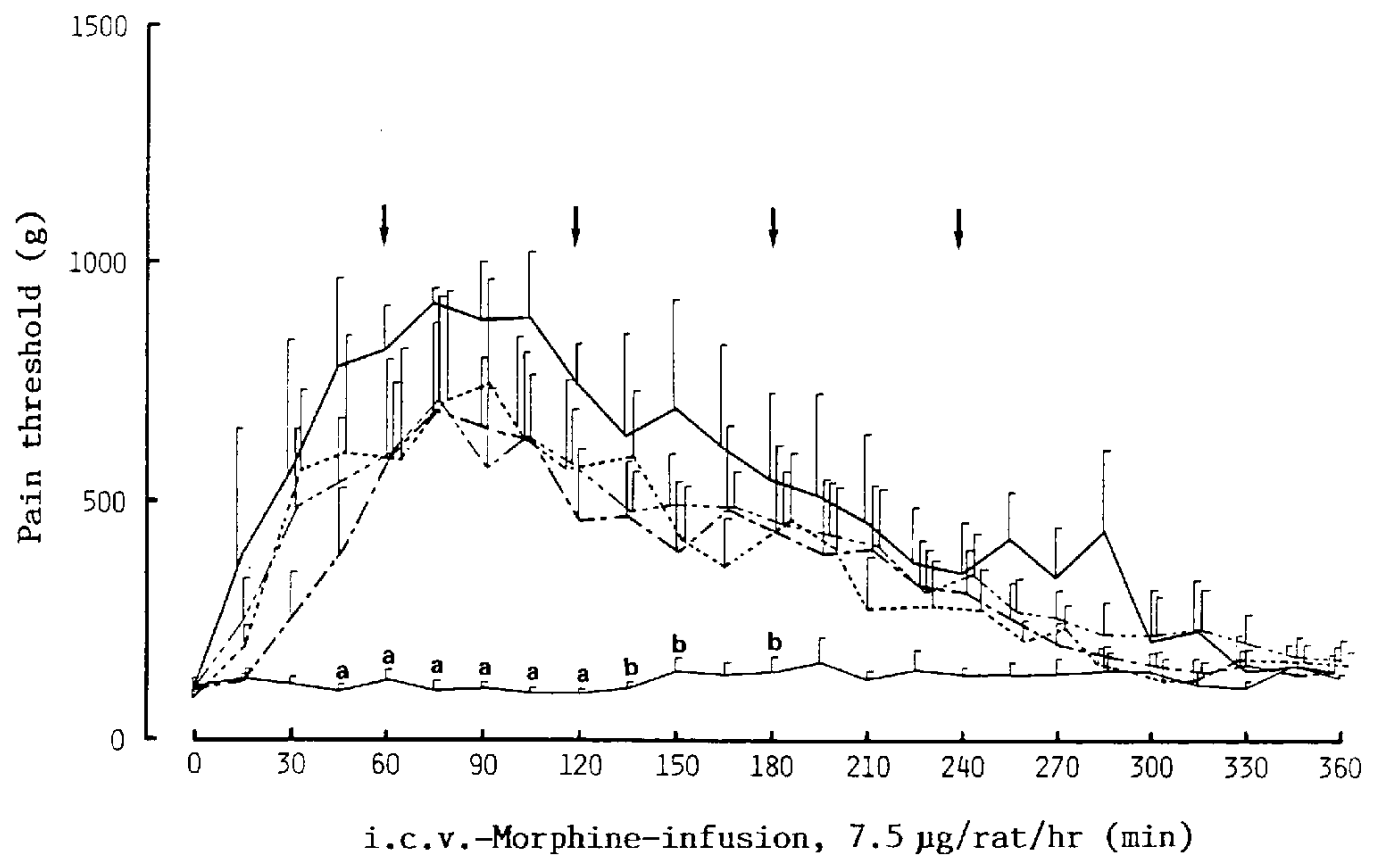

Fig. 7. Effect of dynorphin-(1-13), i.c.v, on acute tolerance developed by continuous i.c.v.-infusion of morphinc estimated by the hind paw pressure test. Morphine was i.c.v.-infused continuously at the rate of $7.5 \mu \mathrm{g} / \mathrm{rat} / \mathrm{hr}$ for $6 \mathrm{hr}$. Dynorphin-(1-13), i.c.v. was injected $1,2,3$ and $4 \mathrm{hr}$ after the morphine infusion (arrows indicate the injection time of dynorphin-(1-13) in each dose). ——: Sal + SAL $(\mathbf{n}=4)$, — $:$ MOR + SAL $(\mathrm{n}=3) ;---:$ MOR + DYN, $2 \mu \mathrm{g} / \mathrm{rat}$ $(\mathrm{n}=6) ;-\cdots-:$ MOR $+\mathrm{DYN}, 10 \mu \mathrm{g} / \mathrm{rat}(\mathrm{n}=5) ; \cdots:$ MOR $+\mathrm{DYN}, 30 \mu \mathrm{g} / \mathrm{rat}(\mathrm{n}=5)$. Sal, continuous i.c.v.-infusion of saline; MOR, continuous i.c.v.-infusion of morphine; SAL, saline, i.c.v.-treatment; DYN, dynorphin-(1-13), i.c.v.-treatment. Each value is the mean, and vertical bars indicate the S.E.M. No statistical difference among the four MOR-infused groups at each time after MOR infusion (Newman-Keuls test). Differs from MOR + SAL. (Student's $t$-test). ${ }^{3} \mathrm{P}<0.01$, ${ }^{\mathrm{b}} \mathrm{P}<0.05$. 
DYN at $2-30 \mu \mathrm{g} / \mathrm{rat}$, i.c.v. was injected 4 times; i.e., after 1, 2, 3, and $4 \mathrm{hr}$, of MOR infusion. No significant changes of MAX were produced by DYN at 2$30 \mu \mathrm{g} /$ rat, i.c.v. A decrease in the pain thresholds followed MAX during MOR infusion combined with DYN and the decreases in the groups treated with DYN at 2, 10 and $30 \mu \mathrm{g}$ were significant $(75 \mathrm{~min}-360 \mathrm{~min}$ : $\mathrm{F}(19,100)=2.41, \mathrm{P}<0.05 ; 75 \mathrm{~min}-360 \mathrm{~min}: \mathrm{F}(19,80)$ $=2.34, \mathrm{P}<0.05 ; 90 \mathrm{~min}-360 \mathrm{~min}: \mathrm{F}(18,76)=2.61, \mathrm{P}$ $<0.01$, respectively), indicating the development of MOR tolerance even with the coadministration of DYN. The AUCs for groups given MOR combined with saline, i.c.v., DYN at $2 \mu \mathrm{g} / \mathrm{rat}$, DYN at $10 \mu \mathrm{g} / \mathrm{rat}$ and DYN at $30 \mu \mathrm{g} /$ rat were $143.9 \pm 42.1(\mathrm{n}=3), 86.5$ $\pm 27.2(\mathrm{n}=6), 101.8 \pm 27.1(\mathrm{n}=5)$ and $99.9 \pm 38.7$ $(\mathrm{n}=5)$, respectively. There was no significant difference among the AUCs in each group. Single treatment with DYN at $2-30 \mu \mathrm{g} / \mathrm{rat} 1 \mathrm{hr}$ after or $5 \mathrm{~min}$ before the i.c.v.-infusion of MOR also did not affect the AUC and MAX (data not shown). These results indicate that the development of acute tolerance by continuous i.c.v.-MOR-infusion was not influenced by DYN at 2 $30 \mu \mathrm{g} / \mathrm{rat}$, i.c.v.

\section{DISCUSSION}

The antinociceptive effect of DYN at $30 \mu \mathrm{g} / \mathrm{rat}$, i.c.v. was demonstrated by the hind paw pressure test (Fig. 1), and the degree of increase in pain threshold was the same as that reported by Hayes et al. (11). A dose-related antinociceptive effect of DYN at 2-30 $\mu \mathrm{g} / \mathrm{rat}$, i.c.v. was also detected by the $\mathrm{AcOH}$ writhing test in rats (Fig. 2) as in mice $(10,12)$. The abnormal behavior, barrel-rolling, was elicited by DYN, disappearing within $2-3 \mathrm{~min}$ and $7-10 \mathrm{~min}$ after DYN at 10 and $30 \mu \mathrm{g} / \mathrm{rat}$, i.c.v., respectively. The estimation of pain thresholds by the hind paw pressure test started at $10 \mathrm{~min}$ (Fig. 1) or $15 \mathrm{~min}$ (Figs. 6 and 7) after DYN. $\mathrm{AcOH}$ solution was injected $5 \mathrm{~min}$ after DYN, and writhings were observed for $60 \mathrm{~min}$ after $\mathrm{AcOH}$. It is thus assumed that the influence of DYN induced abnormal behavior on hind paw pressure and $\mathrm{AcOH}$ writhing tests might be minimal. A large dose of naloxone (10 $\mathrm{mg} / \mathrm{kg}$, s.c.), which had no suppressive effect on the abnormal behavior induced by DYN, in agreement with a previous paper (8), partially antagonized the antiwrithing effect of DYN at $30 \mu \mathrm{g} / \mathrm{rat}$. Therefore, it is suggested that the anti-writhing effect of DYN is mediated by the kappa-receptor, for which naloxone has low affinity (27).

The potency of the anti-writhing effect of DYN was compared with those of $\beta$-endorphin, MOR and Metenkephalin (Table 1). Based on the molar dose that produced almost equi-antinociceptive effects, the order of potency of the anti-writhing effect was $\beta$-endorphin, MOR, DYN and Met-enkephalin. Our results, showing that the anti-writhing potency of Met-enkephalin (deltaagonist) was much lower than those of other agonists (mu- or kappa-agonist) are in agreement with the reports that antinociception against a visceral chemical nociceptive stimulus ( $\mathrm{AcOH}$ writhing) involves agonist interaction with $m u$ - and/or kappa-receptors $(28,29)$. The present results are also consistent with previous reports that the antinociceptive effects of MOR, i.c.v. are more potent than those of DYN, i.c.v. as estimated by the hind paw pressure test (11), tail pinch test (9) and AcOH-writhing test (10), and that $\beta$-endorphin, i.c.v. was more potent than dynorphin- $(1-17)$, i.c.v. in the cold water tail flick test (14).

Recently, Gulati and Bhargava (20) reported that the brain and spinal cord kappa-receptors were up-regulated in MOR tolerant mice. Actually, it had been reported that the cataleptic effect of DYN, i.c.v. was potentiated in rats tolerant to a mu-opioid-agonist, sufentanyl (30), and that the elevation of plasma corticosterone induced by kappa-agonists was more prominent in MOR tolerant rats than in naive ones (21). However, there has been no report on the antinociceptive effect of DYN, i.c.v. in MOR tolerant rats. The present study provides evidence that the anti-writhing effect of DYN was neither potentiated nor decreased in MOR tolerant rats (Fig. 4). The cataleptic effect of DYN was partially reversed by large doses of naloxone (8) but it is not clear whether or not the cataleptic effect is mediated by kappa-receptors (30). Both the plasma corticosterone increase induced by kappa-agonists $(21,31)$. and DYNantinociception are thought to be mediated by kappareceptors, but the influence of MOR tolerance on the kappa-agonists-induced increase in plasma corticosterone and DYN-antinociception were not identical. This difference may result from the different sites of action that participate in plasma corticosterone increase and antinociception.

Very controversial results were obtained about DYN effects on MOR analgesia. An antagonistic effect of DYN, i.c.v. on MOR (s.c. or i.c.v.) analgesia in naive mice has been shown by the radiant heat tail flick test $(15,22)$. However, in the present study, DYN, i.c.v. rather augmented MOR (i.c.v.) analgesia in naive rats by the AcOH writhing test (Fig. 5). MOR has been shown to inhibit the SP release evoked by mechanical stimuli from the spinal dorsal horn of the rabbit (23) and that evoked by high $\mathrm{K}^{+}$from superfused slices of the rat spinal trigeminal nucleus (32). Dynorphin-(1$17)$, i.c.v. has been shown to reduce SP release from the rat spinal dorsal horn evoked by noxious cold sti- 
muli (13) and from the trigeminal nerve evoked by electrical trasmural stimulation of the rabbit iris sphincter muscle (33). These results suggest that antinociception produced by MOR and DYN have at least in part a common underlying mcchanism, inhibiting SP release. A noxious heat stimulus was found to produce no significant increase in SP release from the spinal dorsal horn (13) and the antinociceptive effect of DYN could not be demonstrated by the radiant heat tail flick test (15). Therefore, if a visceral nerve stimulus by $\mathrm{AcOH}$ increases SP release from the spinal dorsal horn, the present result that the anti-writhing effect of MOR was augmented by DYN may be explained by the mechanism that MOR and DYN reduce SP release synergistically

On the other hand, the hot thermal stimulus increased somatostatin (SST) release, but not SP, in the rabbit spinal dorsal horn and MOR inhibited the release of SST (24). As MOR analgesia can be demonstrated by analgesic assays using both mechanical and hot thermal stimuli (28), it is suggested that one of the mechanisms of MOR analgesia is due to the inhibition of SP or SST release induced by noxious stimuli. Dynorphin- $(1-17)$, i.c.v. inhibited SP release, but not SST release (13). These results led us to assume that dynorphin may be ineffective on MOR analgesia estimated by the radiant heat tail flick test. In fact, the synthetic opioid agonist, [D-Pro $\left.{ }^{10}\right]$-dynorphin- $(1-11)$, which is a highly potent and selective ligand for kappareceptors, did not affect MOR analgesia estimated by the radiant heat tail flick test (12), and $\mathrm{U}-50,488 \mathrm{H}$, which is a kappa-agonist that reduces the SP release evoked by noxious cold stimuli (13), did not affect the MOR analgesia estimated by hot plate test (24). Furthermore, DYN, s.c. potentiated the MOR-induced depression of the respiratory rate in mice (34). In the present study, DYN potentiated MOR antinociception estimated by the $\mathrm{AcOH}$ writhing test (Fig. 5), but did not affect MOR antinociception estimated by the hind paw pressure test (Figs. 6 and 7), and DYN antagonized MOR antinociception estimated by the radiant heat tail-flick test $(15,22)$. These results suggest that DYN modulates MOR action, but the effects of DYN are dependent upon the action of MOR and the assay methods to estimate MOR action.

The involvement of dynorphin in MOR tolerance have been suggested by evidence that the action of DYN on MOR analgesia in a naive state was different from that in the MOR tolerant state (22), but the direct evidence of DYN action on the development of MOR tolerance has not been reported. Analgesic tolerance to i.c.v.-, intrathecal (i.t.)- and i.c.v. + i.t.-MOR had been reported to be different (35). It is known that MOR is distributed in both brain and spinal cord after s.c.-injection, but predominantly into the brain after i.c.v.-injection. Then the effects of DYN on acute MOR tolerance developed by s.c.- and i.c.v.-MORinfusion were investigated.

Acute tolerance was developed during continuous s.c.-infusion of MOR for $6 \mathrm{hr}$ (Fig. 6), being consistent with the previous report (36). Multiple i.c.v.-injection of DYN at $2-30 \mu \mathrm{g} / \mathrm{rat}$ did not significantly change the MAX and the AUC for s.c.-MOR infusion and acute tolerance was developed by s.c.-MOR infusion combined with multiple i.c.v.-DYN

Continuous i.c.v.-infusion of MOR also resulted in development of acute tolerance to MOR antinociception. Multiple i.c.v.-injection of DYN at $2-30 \mu \mathrm{g} / \mathrm{rat}$ did not produce any significant influence on the MAX and the AUC for i.c.v.-MOR infusion, and acute tolerance was developed by i.c.v.-MOR infusion combined with multiple DYN.

These results are incompatible with the report that the development of tolerance to MOR analgesia was blocked by the systemic coadministration of a selective kappa-opioid-agonist, U-50,488H (25). This discrepancy may be caused at least in part by the following two differences: i) Difference in the duration of action of DYN and U-50,488H: DYN was degraded largely within 10 min during in vivo incubation (8), and the antinociceptive effects of DYN were evident for $20 \mathrm{~min}$ (Fig. 1) $-60 \mathrm{~min}$ (Table 1). On the other hand, U$50,488 \mathrm{H}(25 \mathrm{mg} / \mathrm{kg}$, i.p.) showed antinociception for $240 \mathrm{~min}(19)$ and hypothermia for $90-240 \mathrm{~min}(19,37)$. ii) Difference in the model of MOR tolerance: The acutely developed tolerance (within hours) is different from the slowly developed one (for several days); i.e., the former is blocked but the latter is not blocked by cycloheximide, a protein synthesis inhibitor (38). MOR tolerance in the present experiment was developed within $6 \mathrm{hr}$, while that in the previous report $(25)$ was developed for $3-7$ days.

\section{REFERENCES}

1 Goldstein, A., Tachibana, S., Lowney, L.I., Hunkapiller, M. and Hood, L.; Dynorphin-(1-13), an extraordinarily potent opioid peptide. Proc. Natl. Acad. Sci. U.S.A. 76, 6666-6670 (1979)

2 Chavkin, C., James, I.F. and Goldstein, A.: Dynorphin is a specific endogenous ligand of the opioid receptor. Science 215, $413-415$ (1982)

3 Fallon, J.H. and Leslic, F.M.: Distribution of dynorphin and enkephalin peptides in the rat brain. J. Comp. Neurol. 249, $293-336$ (1986)

4 Miller, K.E. and Seybold, V.S.: Comparison of met-enkephalin, dynorphin $A$, and neurotensin immunoreactive neurons in the cat and rat spinal cords: II. Segmental differences in the 
marginal zone. J. Comp. Neurol. 279, 619-628 (1989)

5 Mansour, A., Khachaturian, H., Lewis, M.E., Akil, H. and Watson, S.J.: Autoradiographic differentiation of $m u$, delta and kappa opioid receptors in the rat forebrain and midbrain. J. Neurosci. 7, 2445 - 2464 (1987)

6 Traynor, J.R. and Wood, M.S.: Distribution of opioid binding sites in spinal cord. Neuropeptides 10, 313-320 (1987)

7 Millan, M.J., Millan, M.H., Czlonkowski, A., Hollt, V., Pilcher, C.W.T., Herz, A. and Colpaert, F.C.: A model of chronic pain in the rat: Response of multiple opioid systems to adjuvant-induced arthritis. J. Neurosci. 6, 899-906 (1986)

8 Herman, B.H., Leslie, F. and Goldstein, A.: Behavioral effects and in vivo degradation of intraventricularly administered dynorphin-(1-13) and D-Ala ${ }^{2}$-dynorphin-(1-11) in rats. Life Sci. 27, 883-892 (1980)

9 Kaneko, T., Nakazawa, T., Ikeda, M., Yamatsu, K., Iwama, T., Wada, T., Satoh, M. and Takagi, H.: Sites of analgesic action of dynorphin. Life Sci. 33, Supp. I, 661 - 664 (1983)

10 Nakazawa, T., Ikeda, M., Kaneko, T. and Yamatsu, K.: Analgesic effects of dynorphin-A and morphine in mice. Peptides 6, $75-78$ (1985)

11 Hayes, A.G., Skingle, M. and Tyers, M.B.: Antinociceptive profile of dynorphin in the rat. Life Sci. 33, Supp. I, 657-660) (1983)

12 Gairin, J.E., Gout, R., Meunier, J.-C. and Cros, J.: [DPro $\left.^{10}\right]$-dynorphin $(1-11)$ is a kappa-selective opioid analgesic in mice. J. Pharmacol. Exp. Ther. 245, $995-1001$ (1988)

13 Tiseo, P.J., Adler, M.W. and Liu-Chen, L.-Y.: Differential release of substance $\mathbf{P}$ and somatostatin in the rat spinal cord in response to noxious cold and heat; Effect of dynorphin $A$ (1-17). J. Pharmacol. Exp. Ther. 252, $539-545$ (1990)

14 Tiseo, P.J., Geller, E.B. and Adler, M.W.: Antinociceptive action of intracerebroventricularly administered dynorphin and other opioid peptides in the rat. J. Phamacol. Exp. Ther. 246, $449-453$ (1988)

15 Friedman, H.J., Jen, M.F., Chang, J.K., Lee, N.M. and Loh, H.H.: Dynorphin: A possible modulatory peptide on morphinc or $\beta$-endorphin analgesia in mouse. Eur. J. Pharmacol. 69, 357-360 (1981)

16 Millan, M.J.: Multiple opioid systems and pain. Pain 27, $303-347$ (1986)

17 Holaday, J.W., Hitzemann, R.J., Currell, J., Tortella, F.C. and Belenky, G.L.: Repeated electroconvulsive shock or chronic morphine treatment increases the number of ${ }^{3} \mathrm{H}$ - $\mathrm{D}$ $\mathrm{Ala}^{2}$-D-Leu ${ }^{5}$-enkephalin binding sites in rat brain membranes. Life Sci. 31, 2359-2362 (1982)

18 Rothman, R.B., Danks, J.A., Jacobson, A.E., Burke, T.R., Rice, K.C., Tortella, F.C. and Holaday, J.W.: Morphine tolerance increases $\mu$-noncompetitive $\delta$ binding sites. Eur. J. Pharmacol. 124, 113-119 (1986)

19 Bhargava, H.N., Gulati, A. and Ramarao, P.: Effect of chronic administration of $\mathrm{U}-50,488 \mathrm{H}$ on tolerance to its pharmacological actions and on multiple opioid receptors in rat brain regions and spinal cord. J. Pharmacol. Exp. Ther. 251, $21-$ 26 (1989)

20 Gulati, A. and Bhargava, H.N.: Up-regulation of brain and spinal cord kappa opioid receptors in morphine tolerant-dependent mice. FASEB J. 2, A368 (1988)

21 Iyengar, S., Kim, H.S. and Wood, P.L.: Kappa opiate agonists modulate the hypothalamic-pituitary-adrenocortical axis in the rat. J. Pharmacol. Exp. Ther. 238, $429-436$ (1986)

22 Tulunay, F.C., Jen, M.F., Chang, J.K., Loh, H.H. and Lee, N.M.: Possible regulatory role of dynorphin on morphineand $\beta$-endorphin-induced analgesia. J. Pharmacol. Exp. Ther. 219, $296-298$ (1981)

23 Kuraishi, Y., Hirota, N., Sugimoto, M., Satoh, M. and Takagi, H.: Effects of morphine on noxious stimuli-induced release of substance $\mathbf{P}$ from rabbit dorsal horn in vivo. Life Sci. 33, Supp. I, 693-696 (1983)

24 Kuraishi, Y., Hirota, N., Sato, Y., Hino, Y., Satoh, M. and Takagi, H.: Evidence that substance $P$ and somatostatin transmit separate information related to pain in the spinal dorsal hom. Brain Res. 325, 294-298 (1985)

25 Yamamoto, T., Ohno, M. and Ueki, S.: A selective $x$-opioid agonist, U-50,488H, blocks the development of tolerance to morphine analgesia in rats. Eur. J. Pharmacol. 156, $173-176$ (1988)

26 de Balbian Verster, F., Robinson, C.A., Hengeveld, C.A. and Bush, E.S.: Freehand cerebroventricular injection technique for unancsthctized rats. Life Sci. 10, Part 1, 1395-1402 (1971)

27 Von Voightlander, P.F., Lahti, R.A. and Ludens, J.H.: U50,488: A selective and structurally novel non-mu (kappa) opioid agonist. J. Pharmacol. Exp. Ther. 224, 7-12 (1983)

28 Tyers, M.B.: A classification of opiate receptors that mediate antinociception in animals. Br. J. Pharmacol. 69, 503-512 (1980)

29 Ward, S.J. and Takemori, A.E.: Relative involvement of $m u$, kappa and delta receptor mechanisms in opiate-mediated antinociception in mice. J. Pharmacol. Exp. Ther. 224, 525-530 (1983)

30 Herman, B.H. and Goldstein, A.: Cataleptic effect of dynorphin- $(1-13)$ in rats made tolerant to a $m u$ opioid receptor agonist. Neuropeptides 2, $13-22$ (1981)

31 Eisenberg, R.M.: Plasma corticosterone changes in responsc to central or peripheral administration of kappa and sigma opiate agonists. J. Pharmacol. Exp. Ther. 233, 863-869 (1985)

32 Jessell, T.M. and Iversen, L.L.: Opiate analgesics inhibit substance $P$ release from rat trigeminal nucleus. Nature $\mathbf{2 6 8}$, $549-551$ (1977)

33 Ueda, N., Muramatsu, I. and Fujiwara, M.: Dual effects of dynorphin- $(1-13)$ on cholinergic and substance P-ergic transmissions in the rabbit iris sphincter muscle. J. Pharmacol. Exp. Ther. 232, $545-550$ (1985)

34 Woo, S.K., Tulunay, F.C., Loh, H.H. and Lee, N.M.: Effect of dynorphin-(1-13) and related peptides on respiratory rate and morphine-induced respiratory rate depression. Eur. J. Pharmacol. 96, 117-122 (1983)

35 Roerig, S.C., O'Brien, S.M., Fujimoto, J.M. and Wilcox, G.L.: Tolcrance to morphine analgesia: decreased multiplicative interaction between spinal and supraspinal sites. Brain Res. 308, 360-363 (1984)

36 Kaneto, H., Koida, M. and Nakanishi, H.: Studies on physical dependence inducible by hours exposure of mice to morphine. Japan. J. Pharmacol. 22, 755 - 766 (1972)

37 Bhargava, H.N., Ramarao, P. and Gulati, A.: Effects of morphine in rats treated chronically with $\mathrm{U}-50,488 \mathrm{H}$, a $x$ opioid receptor agonist. Eur. J. Pharmacol. 162, 257-264 (1989)

38 Kaneto, H., Kosaka, N. and Hirota, N.: Timing of cycloheximide administration and inhibition of the development of analgesic tolerance to morphine. Life Sci. 31, 2351 - 2354 (1982) 